\title{
EXPLORING SPATIAL PARAMETERS TO EVALUATE HUMAN WALKING ACCESSIBILITY OF URBAN GREEN SPACE
}

\author{
J. Jia ${ }^{1, *}$ S. Zlatanova ${ }^{1}$, K. Zhang ${ }^{2}$ \\ ${ }^{1}$ UNSW, School of Built Environment, Sydney, New South Wales, Australia - (jing.jia.1, s.zlatanova)@unsw.edu.au \\ ${ }^{2}$ UNSW, School of Civil and Environmental Engineering, Sydney, New South Wales, Australia - kefeng.zhang@unsw.edu.au
}

Commission IV

KEY WORDS: Space Syntax, Sustainable Urban Development, Accurate Design, Green Infrastructure, 3D Spatial Model

\begin{abstract}
:
With the growth of urban population and the increasing urban density, urban green space has become a kind of precious and limited resources. It not only has a positive impact on the health of urban residents with high work-life pressure but also offers opportunities as part of blue-green solutions for sustainable urban water management. Therefore, to effectively utilise the limited green spaces, experts are exploring a way of organising the green space layout to balance human needs and other urban developing requirements (e.g., in this case, urban stormwater management) within the certain common area. With this target, translating the space accessibility to human and other urban developments on green space into space parameter is a critical step to organize space model for the multi-functional green space. Although there are plenty of existing spatial parameters developed for evaluating human accessibility (such as travel distance, land-use, spatial connectivity etc.), there isn't a way to organize them to satisfy the diverse evaluation needs from different research purposes. Besides, most of them are suitable for analyzing space on a city scale or at least a precinct scale in a 2D model. To the accurate design on a micro-scale, it is still a big challenge. The reason is some parameters for city analysis don't work on a micro-scale, and some parameters should be reorganised in the evaluation algorithm or should include more micro-scale factors. Thus, this paper, based on the characteristics of human behaviour, redefines the complex concept- accessibility and develop measurable parameters with feasible factors on micro-scale. Overall, this paper presents: (1) a new definition of walking accessibility of green space; (2) evaluation criteria (3) parameters (depth and Integration) reflecting connectivity criteria (4) Parameters (travel time and speed, slope, direction changes) relating travel distance criteria with updated evaluation algorithm and factors. This paper aims at useful spatial parameters and evaluation measures that are applicable to integrate human needs within multi-functional green space design, especially green stormwater management design.
\end{abstract}

\section{INTRODUCTION}

\subsection{Background}

The academia has widely acknowledged that contacts with nature can benefit human health and well-being (Lee, Maheswaran, 2011, Harting et al., 2014). Landscape designers and researchers believe that the green space layout (morphology) can create scene beauty which benefits human (Wang et al., 2020b, Harris et al., 2018). The green space with vegetation can create open space for public activity, also relatively private space for individual relax (Wang et al., 2020a, Bertram, Rehdanz, 2015). Meanwhile, to support sustainable and resilient urban development in the rapid urbanization era, managing the natural disaster with urban green space has promoted widely (World Resources Institute, 2019, Saxena, 2016). In addition, green space has a positive role in removing pollutants from water and absorbing runoff on-site to reduce the risk of flooding (Lin, Kongjian, 2012, Prodanovic et al., 2017, Zhang et al., 2020, Wong et al., 2013). As experts from diverse disciplines focus on the effective use of green space for specific purposes, a new thorny issue emerged is how to meet different requirements on functions of the green space with limited resources in a highdensity urban area. For example, for the stormwater issues, the countries around the world have proposed several green stormwater management concepts, such as Low Impact Development (LID), Water Sensitive Urban Design (WSUD), Sponge City
(SC), etc. (Fletcher et al., 2015, Li et al., 2017). While they can effectively manage stormwater with green space, they occupy the green space without much consideration about the human daily needs. On the contrary, green space researches of human health only care about how to organize the space layout, plant species and facilities for human needs without any consideration on the interaction with green water management. The awkward situation is mainly caused by two reasons. One is stormwater management and human health investigations are led by a different professional. The other one is, to the complex concept-space accessibility, while there are many spatial parameters provided for space analysis and design, they are mainly proposed from macro scale (i.e. city or precinct scale) and focus on the transport planning, property price etc. Thus it is too difficult to co-work with stormwater management design or other engineering research in the same spatial model. Especially, regarding optimizing green space design on micro-scale (such as $1000 \times 1000 \mathrm{~m}$ or $500 \times 500 \mathrm{~m}$ ), and cooperating with other professionals, there is still a research gap for developing the spatial parameters and measures for evaluating space accessibility of human. Therefore, caring for human and sotrmwater management are the both key targets of sustainable urban development (United Nations Sustainable Development, 2020)).This research intends to develop the parameters of space accessibility based on the habit of human behaviour to support multifunctional stormwater management space design and improve the visiting experience.

\footnotetext{
* Corresponding author
} 


\subsection{Literature review}

There are several existing spatial analysis parameters developed for evaluating accessibility. We reviewed these parameters to identify whether they can be used directly for walking accessibility analysis in small scale.

Landscape Resistance has been used by Yu et al. (1999) to evaluate the accessibility of green space in city scale by assigning a relative resistance value to a certain land-use (Kongjian et al., 1999, Huabin et al., 2009). But as it cannot assign an accurate resistance value to space purely based on land-use and does not include the road network context within the analysis, this approach can only be used to support design decision in urban planning level. In a neighbourhood area or a superblock, with limited attributes of land-use, it cannot deliver a useful analysis result.

Distance has been treated as an important parameter to determine the degree of connectivity between two points and evaluate the accessibility for years (Coombes et al., 2010, Irvine et al., 2013). The certain distance threshold has been developed to indicate the ideal distance servicing for people walkability (Grahn, Stigsdotter, 2003). With a certain distance threshold (such as 500 meters), it can create a distance buffer to indicate a certain scope where walking accessible the center of buffer (Ulmer, Hoel, 2003, Munoz-Raskin, 2010). But this parameter cannot reflect the influence of the density and structure of the road network on the space accessibility.

Number of road intersections is also used to evaluate the space accessibility. The number of intersections within a selected scope can indicate the road density and the degree of space connectivity (Southworth, Owens, 1993). It implies that the more intersections, the higher possibility of visiting from surroundings. But with this method, we can just characterize the road density and potential visiting possibility of an area in aggregate. Regarding the degree of accessibility for a certain location, the number of intersection cannot provide a clear answer.

Meanwhile, within some studies, accessing of green space is assessed by Cumulative Opportunity, which indicates that contacting with small nature elements (tree canopy) does matter as well (Ekkel, de Vries, 2017). This method is also used to reflect the frequency of contacting green space accessibility in a whole area without the ability to evaluate the accessibility for the specific road segment or block.

The space relative asymmetric value, integration value, reach metric, directional distance developed from Space Syntax theory are also adopted to test the accessibility of green space by analysing the complexity and connectivity of road network around green space (Li et al., 2019, Peponis et al., 2008). Compared to the other methods, the space syntax parameters can both reflect the more accurate degree of connectivity for the area in aggregate and calculate the cohesion level for a certain road segment or a specific block. But as Space Syntax does not consider the structure of a road network from the individual behaviour perfective with its factors, such as slope, number of direction changes, etc., there is still a research gap for estimating space accessibility.

The accessibility analysis parameters mentioned above is used to support different research goals with different space accessibility definition. Based on the review we can conclude that, due to the complexity of accessibility concept, the accessibility evaluation should respect the research context and target. If not, the careless use of spatial parameters with the existing research methods would mislead the design decision. The existing accessibility researches mainly focus on property price, transport planning and policymaking etc. , without specific targeting on optimisation of green stormwater management design. Thus, this study will focus on improving a multifunctional green space design by analysing and respecting walking accessibility.

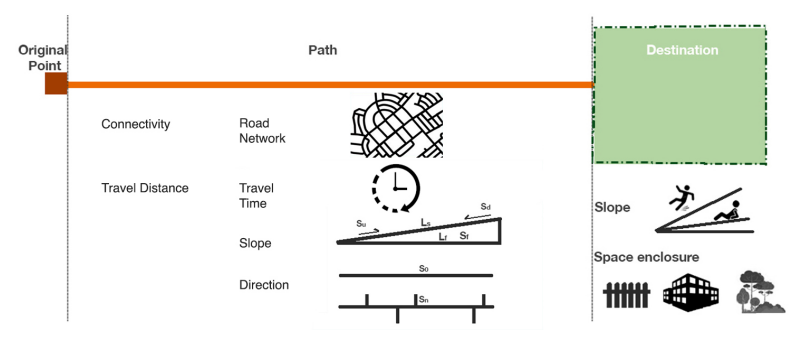

Figure 1. Schematic diagram of walking space structure and impact spatial parameters

We argue that accessibility analysis can provide evidence for space layout design and investment. It means we need the accessibility evaluation to help us to estimate that the potential population can get and use green space and their location. Meanwhile, this research focuses on evaluating the accessibility relating walking path, as walking is the most basic human transport mode and occupies a large part of human daily life. Furthermore, in micro-scale design (such as a precinct), public transport is generally not taken into account. Thus, we concentrate on defining spatial parameters to evaluate accessibility relating walking path to targeted green space.

As we should identify the opportunity and the degree of involvement of human accessing green space, the accessibility can be subdivided into two parts (Figure 1). One is about the walking path, the other is about the quality of green space. Walking path analysis can reflect the relationship between green space location and movement flows. Regarding the quality of green space, it can evaluate the usability of green space from a people perspective. Thus, the parameters can be classified in two groups to estimate:

1. ease of the available paths to the green space;

2. possible access nodes (entrances) to the green space.

To this paper, we will focus on the first group of parameters which relate to the walking path. The paper is organised in six sections. Next section defines the accessibility concerning the walking path and the relevant criteria. Section three elaborates on the first spatial parameter named connectivity. Section four discusses the second parameter, which is travel distance. Section five summarises the paper's work and outlines future research.

\section{DEFINITION OF ACCESSIBILITY AND CRITERIA FOR WALKING PATH}

\subsection{Accessibility relating walking path}

Accessibility has diverse definitions. Except for the definitions of understanding certain things, spatial accessibility still has several meanings. In A Dictionary of Human Geography, it is 
defined as the ease of getting some certain goods or services in a specific location from somewhere (Gregory et al., 2011). From a land-use perspective, space accessibility is translated into 'the potential of opportunities for interaction' (Hansen, 1959). From the mental health perspective, the definition of green space accessibility is organized as consisting of visual contact with natural elements, the ease of reaching nature and active involvement with green area (Pretty et al., 2005). Obviously, the specific definition of accessibility has a strong relationship with the research discipline.

In this study, we just focus on the spatial parameters influencing human activity on the walking path. To make it simple, we use walking accessibility to represent the specific type of accessibility related to the walking path. To support assumption of actual demand on green space, walking accessibility should reflect not only the ease of reaching targeted green spaces by walk but also the access opportunities and potential needs on these green spaces.

\subsection{Evaluation Criteria}

Existing researches have concluded that there is not a perfect solution for evaluating accessibility in all situations (Handy, Niemeier, 1997), but they have developed some basic criteria to drive the feasible accessibility measures. The first one should be sensitive to changes in the transport situation (Geurs, Van Wee, 2004). Although we just focus on the walking mode, the different road conditions still can generate changes in the walking situation, such as walking speed and path choice. The second one should reflect the land-use changes (Geurs, Van Wee, 2004). To this study, the influence of the distribution of the green space should be taken into account within the analysis. Shen (1998) pointed out, to avoid the inaccurate or misleading evaluation output, the measure should include the competition effects into account for accessibility (Shen, 1998). It means that, if its service capacity cannot satisfy the needs on the green space from surroundings, it indicates the green space still is not accessible for the individuals, even the location of green space is well connected with surroundings. From this study perspective, we organized two criteria based on our accessibility definition and existing research:

1. Connectivity: If the green space is located at the street segment with better (worse) connectivity, then the opportunity of accessing the green space would be higher (lower) from any point within the research area.

2. Travel distance: If the travel distance is longer (shorter), then the accessibility of the green space is weaker (stronger). The surrounding environment impacts the travel distance via the changes in walking speed.

These criteria are used to reveal the relationship between the service capability of green space and the human daily needs on it. The firs criteria is independent from human and reflect only the transportation network. The second criteria is human dependant and reflects human abilities, preferences and behaviour. These two criteria can be further considered for inclusion in models for green stormwater management. As mentioned above, the location criteria can just indicate the service level of road infrastructure connecting selected green spaces, but cannot reflect ability of people visiting from the surroundings. Therefore the travel distance criteria should be included. Due to their different nature, it is too hard to integrate both the criteria within one equation. Therefore, this study threats them separately and develops two different approachers to estimate them.

\section{CONNECTIVITY}

In general, connectivity of a road network can be defined as an indicator of 'the availability of guide-way facilities' among the roads within a selected area (Labi et al., 2019). Its analysis is mainly concerned with the network topology. With respect to our study, the connectivity analysis contributes to a better reflection of the interaction between the location of green spaces and the movement flows. We decided to adopt the Space Syntax approach, which is a method widely accepted as an efficient method to quantitatively reflect the space accessibility for diverse applications. (Kim, Sohn, 2002, Li et al., 2019, Alkamali et al., 2017).

In our approach we use Axial Line Analysis which is one of the most popular Space Syntax methods (Kim, Sohn, 2002, Penn, 2003). It forms an axial map to analyse the degree of depth and integration of the intersecting lines by extracting the middle lines of the roads in the research area (Hillier, 2007). Two parameters are used in this approach to measure the connectivity, i.e., the depth of road segments and the degree of integration.

\subsection{Depth}

Depth refers to the number of steps (roads) an individual should take to pass from one node to the other nodes within the road network (Hillier, 2007, Khalesian et al., 2009). The value of Depth is the smallest number of steps taken from the original node to the others. Consequently, we can assign the depth value to each space on the line to get the Mean Depth result. It will be helpful to calculate the integration value at the next step. The equation of depth to calculate the smallest number of road units taken from one node to the others, is shown below.

$$
D_{i}=\sum_{j=1}^{n} d_{i j} ; M D_{i}=\frac{D_{i}}{n-1}
$$

where $\quad D_{i}=$ total depth value of the node i

$d_{i j}=$ shortest path between node $\mathrm{i}$ and $\mathrm{j}$

$n=$ number of nodes

$M D_{i}=$ mean depth value of node $\mathrm{i}$

(Khalesian et al., 2009, Li et al., 2019)

It is worthy noting that, the normal Depth analysis, most of times, is treating the entire road as a unit (line) within the network (Li et al., 2019, McCahill, Garrick, 2008). It is undeniable that such an analysis can express the relatively accurate the relational characteristics of the road, especially the permeability of the roads. But as the focus of our study is the accessibility of green space, the traditional approach could pose a potential risk. The main reason is that the roads are represented by nodes which means the distance or the length of the roads are neglected (Hillier, 2007, Turner, 2007) (see Figure 2). Although both of the main roads where each green space A and B is located at have the same depth value, the location of the green space and the number of the roads connected directly with the green spaces are different. That means, if we assign the depth values of the roads to the green spaces directly, we cannot reflect the actual relational situation within the green spaces and the spatial differences between them.

To avoid this effect, we set the street segments sides of the green spaces as an independent nodes within the network. In Figure 


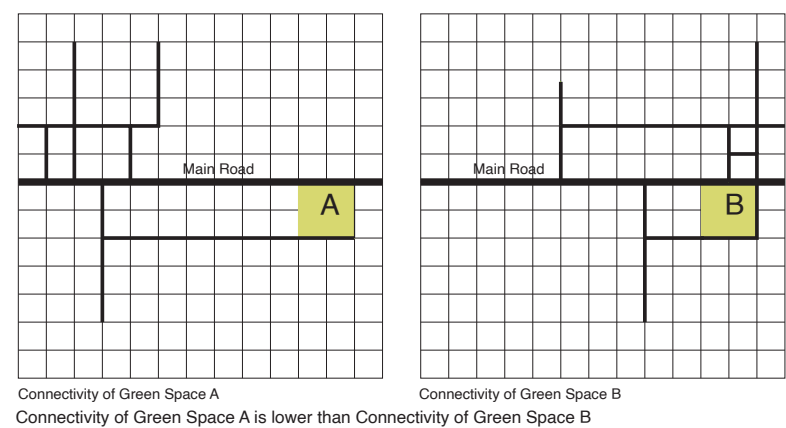

Figure 2. Depth of targeted green space comparison

3 , we compare the depth value of the green space $C$ and $D$ with the different algorithm strategies. For the green space $\mathrm{C}$, the entire main road is set as only one node (Node 1) for the depth analysis. For the green space D, the road segment of the main road adjacent to the green space is divided away from the main road as an independent node (Node 7). Although green space $\mathrm{C}$ and $\mathrm{D}$ have the same location within the same road network, when we define the space nodes in different ways, the spatial network structure and the positions of the green space in the networks are different. The spatial network structure comparison (see Figure 3) illustrates that the spatial structure strategy for green space D would be more accurate. This is because the green space don't have direct connection to the Road 2 and 3. Therefore, in our study we adopt the depth algorithm as mentioned and we reorganize the road network by defining the road segments side as selected spaces or breakaway nodes.

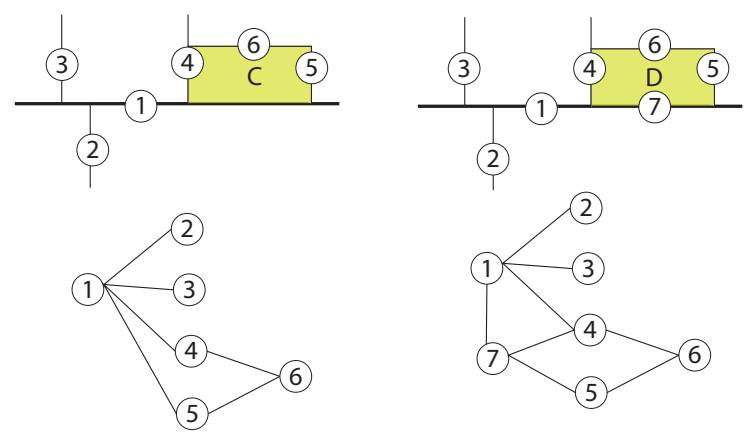

Figure 3. Comparison of green space position with different space structure organization strategy

\subsection{Integration}

Integration value indicates the involvement level of the targeted node (road segment) to the general system (Duan, Wang, 2009, $\mathrm{Li}$ et al., 2019). In other words, the integration value can predict the potential ability to attract the movement flows or the opportunity of individual reaching the specific space. The equation is developed based on relative asymmetry, shown as below (Eq.2).

$$
R A_{i}=\frac{2\left(M D_{i}-1\right)}{n-2} ; I_{i}=\frac{1}{R A_{i}}
$$

where $\quad R A_{i}=$ Relative asymmetry value of the node $\mathrm{i}$ $I_{i}=$ integration of node $\mathrm{i}$

(Khalesian et al., 2009, Li et al., 2019)
There are two sub-categorizes of integration value: global integration and local integration. Global integration is used to evaluate the ease of reaching a specific point (road segment) from anywhere within the whole system. On the contrary, local integration value is the indicator for the involvement degree of a specific point (road segment) and the quality of space structure within a selected scope. As mentioned above, this study intends to identify the potential opportunity for people to access selected green spaces and rank the them to identify the frequently visited green space. Then these spaces can be considered in support of the green infrastructure or green stormwater facility design for optimal cost-efficient green stormwater management.

The integration value cannot directly reflect situations when green spaces connect to the several roads with different integration value. Although, in some researches, it adopts calculating maximum, minimum and average integration for the road segment adjacent to selected space at same time to depict the integration of the green space( $\mathrm{Li}$ et al., 2019). In our study, estimating the opportunity of accessing the green space from all the directions is the critical point, so maximum, minimum and average value cannot ideally satisfy the research target. That's why we employ the sum of integration values per road segment. The included road segments should allow people accessing a green space, no matter whether there is obstacle (Figure 4). Therefore, based on Figure 4, the equation of green space integration should be shown as below (Eq.3).

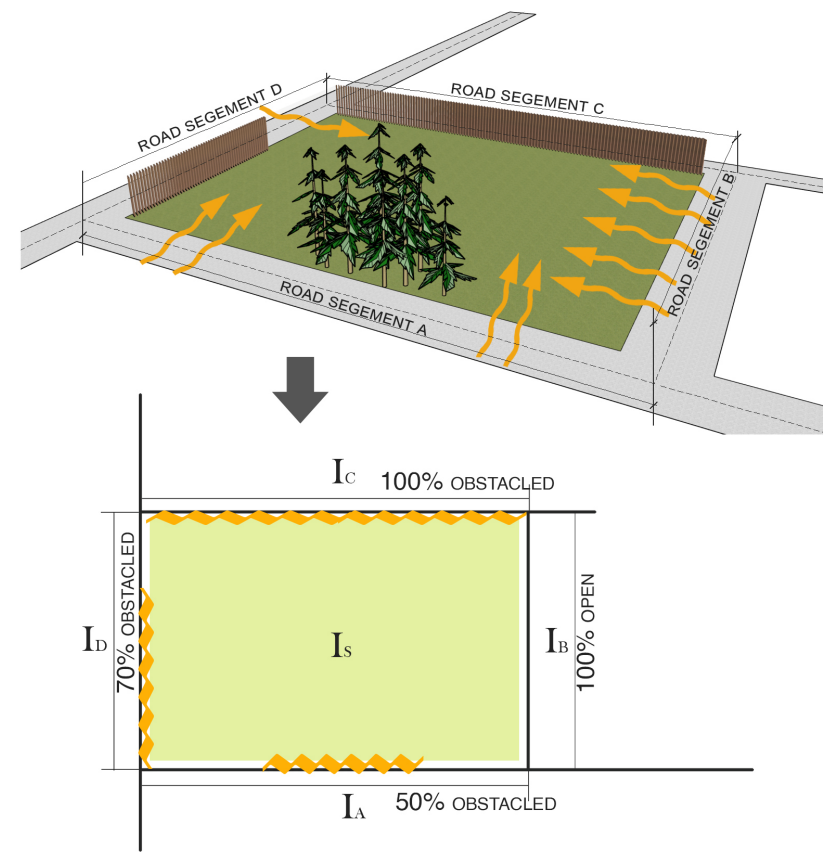

Figure 4. Schematic diagram of green space integration value calculation

$$
I_{s}=I_{A}+I_{B}+I_{D}
$$

$$
\text { where } \quad \begin{aligned}
& I_{s}=\text { Integration value of green space } \\
& I_{A}=\text { integration of segment } \mathrm{A} \\
& I_{B}=\text { integration of segment } \mathrm{B} \\
& I_{D}=\text { integration of segment } \mathrm{D}
\end{aligned}
$$


However, we should be aware that the better connectivity and larger area of the green space cannot improve the ability of an individual to access the green space located out of the regular walking distance catchment(Handy, Niemeier, 1997, Geurs, Van Wee, 2004). Thus, to get a further estimation on the maximum amount of needs on the green space, the paper introduces another parameter - travel distance.

\section{TRAVEL DISTANCE}

Travel distance evaluates whether the individual has the ability to reach the specific green space within a given time (acceptable walking time) and reflects to certain degree the potential human demand on the green space(Weber, Kwan, 2002). Therefore, compared to connectivity, travel distance is generating a more exact scope with walkable distance towards the specific space. It would be the critical variable for estimating the population would daily using the green space. To guarantee the travel distance weight can support the next step of green space servicing capacity, we analyse it based on the following parameters: Travel time and speed, Slope, direction changes.

\subsection{Travel time and speed}

The simplest and widely accepted method for calculating travel distance is based on the travel time and speed. Thus, when we simplify the environment as flat terrain, we can conclude the travel distance by defining an exact travel speed and tolerant travel time (Eq.4). For example, we reference the regular walking speed as 84 meters per minute defined by Nourian et al. (2018) and set the daily walking time as 5 minutes based on the principle of approaching proximity(Nourian et al., 2018). Then we can conclude the daily walking distance of 420 meters. But in this way, we ignored the influence on travel distance from other factors, such as slope.

$$
D_{w}=T * S_{w}
$$

$$
\begin{aligned}
& \text { where } \quad D_{w}=\text { travel distance of walking } \\
& T=\text { Travel time }
\end{aligned}
$$$$
S_{w}=\text { walking speed }
$$

\subsection{Slope}

Slope impacts the travel distance via changing the walking speed. When an individual walk up the slope, his/her walking speed will reduce, and vice versa. Theoretically, if the angle of the terrain is higher, the influence on the speed is greater. Based on the Tobler's hiking function(Tobler, 1993), the walking speed can be weighted with the equation 5 .

$$
S_{w}=6 e^{-3.5\left|\frac{H}{L}+0.5\right|}
$$

where $\quad S_{w}=$ walking speed

$H=$ elevation difference

$L=$ distance

It is worth noting that the slope impacts the speed calculation. It is the walking direction on the path, because going up and going down the same slope would generate different walking speed. Therefore, the research about walking speed calculations in a network always take the double edge directions into account(Nourian et al., 2018). As this study only focuses on the green space as a destination, the returning direction of the walking path is not considered. This means that all walkable paths within the study area head towards the selected green space. Compare to the purely flat context, in the region of downhill towards the green area, the walking distance would longer, and vice versa (Figure 4).
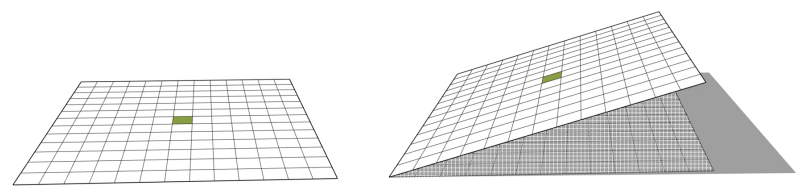

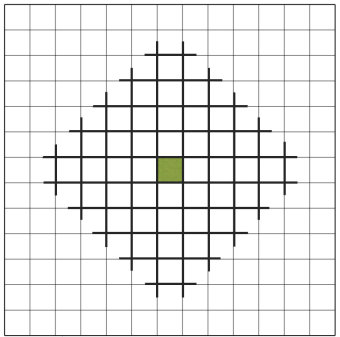

Targeted green space (Destination)

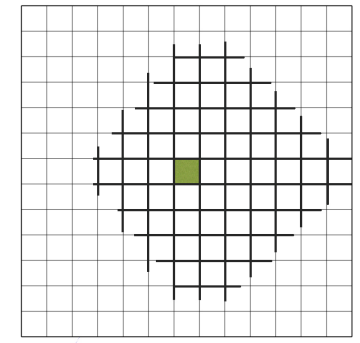

Reachable distance threshold
Figure 5. Schematic diagram of slope influencing on walking distance

As this study is conducted in a micro-scale, we focus on human daily needs on green space. In other words, when an individual prefers to have a rest in the green space without any specific purpose, he/she normally prefers to visit the space nearby. Thus, based on relevant research, we set the travel time at five minutes. Then, we divide the route with slope changes into several segments. With the length of the segment and the elevation (slope) data, we can weight the travel time to the segment. For that, we calculate the needed travel time for the segment connecting the destination and identify how much time is left within the five minutes threshold for walking through the next segment (Chin et al., 2008). Then we calculate the segments step by step until the given time (five minutes) is used up. Figure 6 illustrates this on a schematic network. The first step, we calculate travel time $\left(\mathrm{T}_{k D}\right)$ used for the segment from the destination $\mathrm{P}(D)$ to Point $\left(\mathrm{P}_{k}\right)$. When $5-\mathrm{T}_{D k}>0$, we will continue to calculate the travel time for the next travel segment $\left(\mathrm{T}_{j k}\right)$. Therefore, if an individual can reach the destination from $\mathrm{P}_{o}$ within the given time, the walking distance $\left(\mathrm{D}_{w}\right)$ should be weighted like this: $\mathrm{D}_{w}=\mathrm{L}_{k D}+\mathrm{L}_{j k}+\mathrm{L}_{i j}+\mathrm{L}_{o i}$ (where $\mathrm{L}_{k D}, \mathrm{~L}_{j k}$, $\mathrm{L}_{i j}, \mathrm{~L}_{o i}$ represent the length of these segments. Thus, using the slope factor to calculate walking distance can provide a more accurate range of potential daily users. But the shortcoming is it cannot reflect the preference or potential choice of residents when there is more than one green space provided within the walking distance. To avoid the issue, we introduce another factor - direction -, which takes into account the human choice.

\subsection{Direction changes}

Direction change evaluation in walking distance is used to calculate the complexity of the walking path and indicate whether 


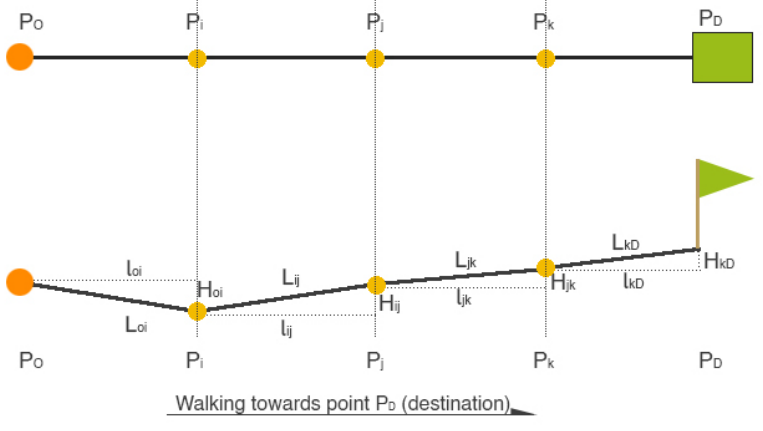

Figure 6. Travel distance calculated with travel time and speed impacted by the slope

people would choose the route. Some studies have argued that fewer direction changes are preferable for most users(Peponis et al., 2008). In general, direction change is a good indicator of path choice because it reflects the human's understanding of the street networks(Hillier, Iida, 2005). Dalton (2003) found that human prefer to choose the path with fewer direction changes (Dalton, 2003). Therefore, we intend to use direction changes to help predict the residents' choice. For example, as shown in Figure 7, assuming that there are two green spaces within the accessible threshold for a residential area, the value of direction changes can help to estimate the probability if the path will be selected. Although empirical research shows that the number of direction changes impact the accessible distance or threshold, there is little support for the way of quantifying its influence.

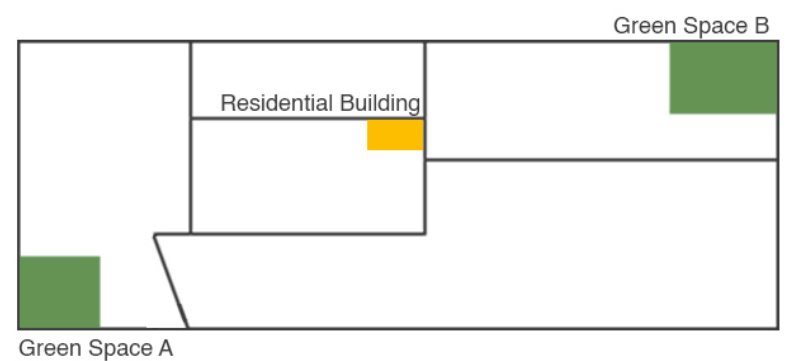

Figure 7. Travel distance calculated with travel time and speed impacted by the slope

As shown in Figure 8, the first factor is the number of direction changes to reach the specific green space. Then the second one is the relational location of the direction changed. We can interpret it as the segment between two turning points, because the shorter segments will require more frequent direction change. Many short segments can make the path less popular(Peponis et al., 2008). Therefore we can reconsider a path with too many segments. As mentioned previously, we are working on the scope within five minutes walking distance, and it should be located within precinct (such as UNSW) or superblock. Within this context, most of the time, we can get the green space by taking at most three or four direction changes. Thus, we can set the direction changes threshold $\delta=4$, then all the path with number of direction changers over the threshold will be remove from the set of accessible paths. Meanwhile, to avoid the Subtle difference of angle in road network (Pretty et al., 2005), we set an angle threshold $\left(\sigma=4^{\circ}\right)$ to neglect the subtle direction changes. Following it, we can start to develop the algorithm for evaluating the influence of direction changes on the level of accessibility

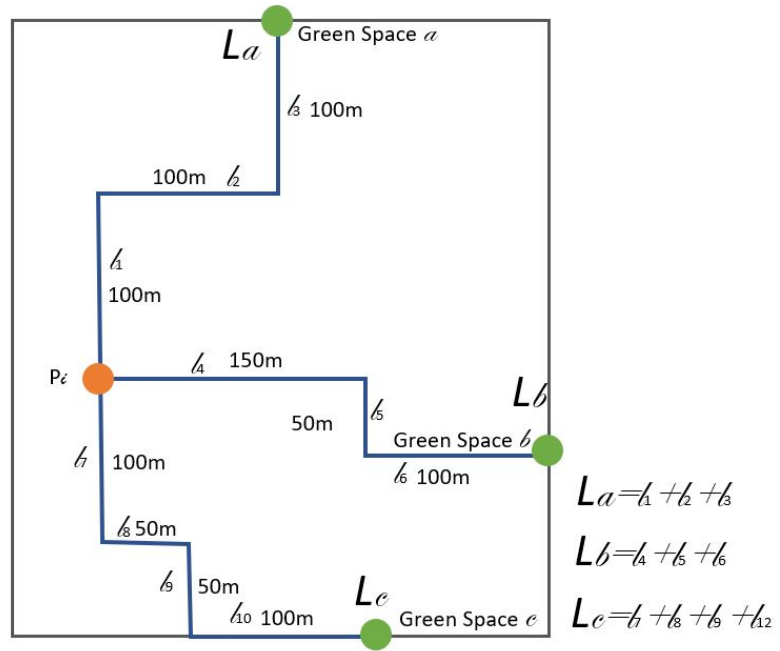

Figure 8. Travel distance calculated with travel time and speed impacted by the slope

1. Original weights: we intend to normalize all the distance within the accessible set, so we adopt the original weights equation to represent the value standardised from the distance (road length).

$$
W_{o_{n}}=\frac{L_{n}-L_{\min }}{L_{\max }-L_{\min }}
$$

where $\quad W_{o_{n}}=$ original weights of $n_{t h}$ path

$L_{n}=$ length of $n_{t h}$ path

$L_{\max }=$ the length of the path with maximum distance

$L_{m \text { min }}=$ the length of the path with minimum distance

(Yan et al., 2020)

2. Shortest path ratio: The output of the original weights is based on the metric length of each path. But in the case of Figure 8 , it is too hard to identify the better one based on the original weights because the path $a$ and path $b$ have the same length. Thus we set shortest path ratio algorithm:

$$
\lambda_{n}=\frac{s l_{\min }}{L_{n}}
$$

where $\quad \lambda_{n}=$ the shortest ratio for $n_{t h}$ path

$L_{n}=$ length of $n_{t h}$ path

$s=$ the segments of the path

$l_{\min }=$ the length of minimum segments

3. Directional ratio: Following the above step, we set the preferred path choice as the path with the same shortest segment but fewer direction changes. As we will get a new segment when we take a turn, so this algorithm we adopt segment to represent the changes. It is shown as the following algorithm:

$$
S=\sum_{1}^{n} \frac{1}{d_{n}} ; D_{n}=\frac{1}{S d_{n}}
$$


where

$$
\begin{aligned}
& S=\text { the sum of reciprocal length to paths } \\
& d_{n}=\text { segments of } n_{t h} \text { segment } \\
& D_{n}=\text { directional ratio }
\end{aligned}
$$

4. Modified weights: With directional ratio and shortest path ratio, we can modify the weights algorithm to reflect the influence of these two factors on accessible level of the selected paths.

$$
W_{m}=\xi W_{o_{n}} \lambda_{n}+(1-\xi) D_{n}
$$

where

$\xi=$ coefficient for the importance of the direction changes

Up to now, we have developed the theoretical background for evaluating the spatial parameters based on the two walking accessibility criteria. At the first step, we adjust the depth and integration parameters to evaluate the situation of the road connecting with others within the system. To get a more accurate estimation on the population accessing green space, we develop a travel distance measure to involve the interaction of human with a road network. We optimize the travel distance algorithm with slope and direction changes.

\section{CONCLUSION}

As existing accessibility studies mainly focus on supporting the transport, property and land-use analysis, this research intends to analyse and extract the spatial parameters for accessibility to facilitate the optimal sustainable stormwater management design in green space. Thus, it can be a test for how the spatial theory supporting multi-functional urban space design.

This study proposed a definition of walking accessibility, relevant evaluation criteria and developed the accessibility evaluation method. It intends to employ spatial parameters (depth, integration, travel time and speed, slope and direction changes) to develop estimate the two evaluation criteria (Connectivity and Travel distance). This method provides important factors neglected by previous studies. Thus, to some extent, the research is endeavouring to optimize the accessibility evaluation method. But we must admit the method is still not tested in real cases, which will be the next step to perform.

This paper develops a theoretical background to rang the accessibility to given green space. More work is needed to provide a method for calculating the potential usage of green space by human. Furthermore, a method for estimating the effect of service facilities (such as benches, tables, etc.) within green spaces should be further developed.

Furthermore, the quality of green space (gated boundary, plants, terrain etc.) is not discussed in this paper. It impacts usability of green space which is another part of accessibility evaluation. Future research will concentrate on the issues discussed above to create a comprehensive accessibility evaluation system to support multi-functional green space layout design, especially for the green stormwater management design.

\section{REFERENCES}

Alkamali, N., Alhadhrami, N., Alalouch, C., 2017. Muscat City expansion and Accessibility to the historical core: Space syntax analysis. Energy Procedia, 115, 480-486.

Bertram, C., Rehdanz, K., 2015. The role of urban green space for human well-being. Ecological Economics, 120, 139-152.

Chin, G. K., Van Niel, K. P., Giles-Corti, B., Knuiman, M., 2008. Accessibility and connectivity in physical activity studies: The impact of missing pedestrian data. Preventive medicine, 46(1), 41-45.

Coombes, E., Jones, A. P., Hillsdon, M., 2010. The relationship of physical activity and overweight to objectively measured green space accessibility and use. Social science \& medicine, 70(6), 816-822.

Dalton, R. C., 2003. The secret is to follow your nose: Route path selection and angularity. Environment and Behavior, 35(1), 107-131.

Duan, Z.-y., Wang, Q., 2009. Road network analysis and evaluation of huizhou city based on space syntax. 2009 International conference on measuring technology and mechatronics automation, 3, IEEE, 579-582.

Ekkel, E. D., de Vries, S., 2017. Nearby green space and human health: Evaluating accessibility metrics. Landscape and urban planning, 157, 214-220.

Fletcher, T. D., Shuster, W., Hunt, W. F., Ashley, R., Butler, D., Arthur, S., Trowsdale, S., Barraud, S., Semadeni-Davies, A., Bertrand-Krajewski, J.-L. et al., 2015. SUDS, LID, BMPs, WSUD and more-The evolution and application of terminology surrounding urban drainage. Urban Water Journal, 12(7), 525542.

Geurs, K. T., Van Wee, B., 2004. Accessibility evaluation of land-use and transport strategies: review and research directions. Journal of Transport geography, 12(2), 127-140.

Grahn, P., Stigsdotter, U., 2003. Landscape architecture and stress. Urban Forestry and Urban Greening, 2(1), 1-18.

Gregory, D., Johnston, R., Pratt, G., Watts, M., Whatmore, S., 2011. The dictionary of human geography. John Wiley \& Sons.

Handy, S. L., Niemeier, D. A., 1997. Measuring accessibility: an exploration of issues and alternatives. Environment and planning A, 29(7), 1175-1194.

Hansen, W. G., 1959. How accessibility shapes land use. Journal of the American Institute of planners, 25(2), 73-76.

Harris, V., Kendal, D., Hahs, A. K., Threlfall, C. G., 2018. Green space context and vegetation complexity shape people's preferences for urban public parks and residential gardens. Landscape research, 43(1), 150-162.

Harting, T., Mitchell, R., De Vries, S., Frumkin, H., 2014. Nature and health. Ann Rev Public Health, 35, 207-28.

Hillier, B., 2007. Space is the machine: a configurational theory of architecture. Space Syntax. 
Hillier, B., Iida, S., 2005. Network effects and psychological effects: a theory of urban movement. Proceedings of the 5th international symposium on space syntax, 1, TU Delft Delft, 553-564.

Huabin, X., Qifeng, Y., Huijun, X., 2009. Green Space Distribution Based on Accessibility and Serving Area [J]. Planners, 25(2), 83-88.

Irvine, K. N., Warber, S. L., Devine-Wright, P., Gaston, K. J., 2013. Understanding urban green space as a health resource: A qualitative comparison of visit motivation and derived effects among park users in Sheffield, UK. International journal of environmental research and public health, 10(1), 417-442.

Khalesian, M., Pahlavani, P., Delavar, M. R., 2009. A GISbased traffic control strategy planning at urban intersections. IJCSNS, 9(1), 166.

Kim, H.-K., Sohn, D. W., 2002. An analysis of the relationship between land use density of office buildings and urban street configuration: Case studies of two areas in Seoul by space syntax analysis. Cities, 19(6), 409-418.

Kongjian, Y., Tiewu, D., Dihua, L. et al., 1999. LANDSCAPE ACCESSIBILITY AS A MEASUREMENT OF THE FUNCTION OF URBAN GREEN SYSTEM [J]. City Planning Review, 8 .

Labi, S., Faiz, A., Saeed, T. U., Alabi, B. N. T., Woldemariam, W., 2019. Connectivity, accessibility, and mobility relationships in the context of low-volume road networks. Transportation research record, 2673(12), 717-727.

Lee, A. C., Maheswaran, R., 2011. The health benefits of urban green spaces: a review of the evidence. Journal of public health, 33(2), 212-222.

Li, H., Ding, L., Ren, M., Li, C., Wang, H., 2017. Sponge city construction in China: A survey of the challenges and opportunities. Water, 9(9), 594.

Li, X., Ni, G., Dewancker, B., 2019. Improving the attractiveness and accessibility of campus green space for developing a sustainable university environment. Environmental Science and Pollution Research, 26(32), 33399-33415.

Lin, M., Kongjian, Y., 2012. Structure the Urban Green Sponge: Study on Planning an Ecological Stormwater Regulation System [J]. Urban Studies, 5, 130-134.

McCahill, C., Garrick, N. W., 2008. The applicability of space syntax to bicycle facility planning. Transportation research record, 2074(1), 46-51.

Munoz-Raskin, R., 2010. Walking accessibility to bus rapid transit: Does it affect property values? The case of Bogotá, Colombia. Transport Policy, 17(2), 72-84.

Nourian, P., Rezvani, S., Valeckaite, K., Sariyildiz, S., 2018. Modelling walking and cycling accessibility and mobility. Smart and Sustainable Built Environment.

Penn, A., 2003. Space syntax and spatial cognition: or why the axial line? Environment and behavior, 35(1), 30-65.

Peponis, J., Bafna, S., Zhang, Z., 2008. The connectivity of streets: reach and directional distance. Environment and Planning B: Planning and Design, 35(5), 881-901.
Pretty, J., Peacock, J., Sellens, M., Griffin, M., 2005. The mental and physical health outcomes of green exercise. International journal of environmental health research, 15(5), 319337.

Prodanovic, V., Hatt, B., McCarthy, D., Zhang, K., Deletic, A., 2017. Green walls for greywater reuse: Understanding the role of media on pollutant removal. Ecological Engineering, 102, 625-635.

Saxena, M. R., 2016. Role of open spaces in disaster management. AGORA.

Shen, Q., 1998. Location characteristics of inner-city neighborhoods and employment accessibility of low-wage workers. Environment and planning B: Planning and Design, 25(3), 345365.

Southworth, M., Owens, P. M., 1993. The evolving metropolis: Studies of community, neighborhood, and street form at the urban edge. Journal of the American Planning Association, 59(3), 271-287.

Tobler, W., 1993. Three presentations on geographical analysis and modeling.

Turner, A., 2007. From axial to road-centre lines: a new representation for space syntax and a new model of route choice for transport network analysis. Environment and Planning B: planning and Design, 34(3), 539-555.

Ulmer, J. M., Hoel, L. A., 2003. Evaluating the accessibility of residential areas for bicycling and walking using gis. Technical report, University of Virginia.

United Nations Sustainable Development, 2020. Health.

Wang, Y., Cheng, Y., Zlatanova, S., Palazzo, E., 2020a. Identification of physical and visual enclosure of landscape space units with the help of point clouds. Spatial Cognition \& Computation, 1-23.

Wang, Y., Zlatanova, S., Yan, J., Huang, Z., Cheng, Y., 2020b. Exploring the relationship between spatial morphology characteristics and scenic beauty preference of landscape open space unit by using point cloud data. Environment and Planning B: Urban Analytics and City Science, 2399808320949885.

Weber, J., Kwan, M.-P., 2002. Bringing time back in: A study on the influence of travel time variations and facility opening hours on individual accessibility. The professional geographer, 54(2), 226-240.

Wong, T. H. F., Allen, R. A., Brown, R. R., Deletic, A., Gangadharan, L., Gernjak, W., Jakob, C., Reeder, M. J., Tapper, N. J., Walsh, C. J., 2013. Stormwater Management in a Water Sensitive City: Blueprint 2013.

World Resources Institute, 2019. Insider: Using nature to prevent disasters.

Yan, J., Zlatanova, S., Diakite, A., 2020. TWO NEW PEDESTRIAN NAVIGATION PATH OPTIONS BASED ON SEMIINDOOR SPACE. ISPRS Annals of Photogrammetry, Remote Sensing \& Spatial Information Sciences, 6.

Zhang, K., Bach, P. M., Mathios, J., Dotto, C. B., Deletic, A., 2020. Quantifying the benefits of stormwater harvesting for pollution mitigation. Water Research, 171, 115395. 